
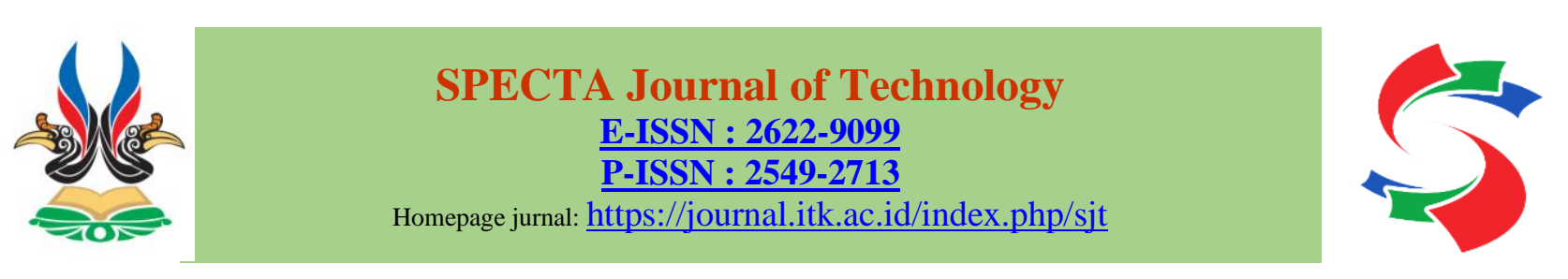

\title{
Kajian Emisi Gas Rumah Kaca Dari Kendaraan Bus Pada Saat Kondisi Diam (Idle) Berdasarkan Persamaan Taylor Di Terminal Purabaya
}

\author{
Rachmanu Eko Handriyono ${ }^{1}$, Nadia Ariyani ${ }^{2}$, Talent Nia Pramestyawati ${ }^{3}$ \\ 1,2,3 Jurusan Teknik Lingkungan, Fakultas Teknik Sipil dan Perencanaan, Institut Teknologi Adhi Tama \\ Surabaya, Surabaya. Email: handriyono.rachmanu@gmail.com
}

\begin{abstract}
Purabaya Station is the largest station in East Java. Bus activity inside the terminal has the potential to increase greenhouse gas (GHG) emissions. This study aims to analyze greenhouse gas emissions from bus activity at idle but with the engine starts at Purabaya Terminal (idle condition). These emissions come from fuel consumption when the bus engine starts. Greenhouse gas parameters in this study are $\mathrm{CO}_{2}, \mathrm{CH}_{4}$, and $\mathrm{N}_{2} \mathrm{O}$ which expressed in $\mathrm{CO}_{2}$ equivalent $\left(\mathrm{CO}_{2 \mathrm{eq}}\right)$. GHG emission calculations use the Taylor equation. This calculation requires data on the number of bus vehicles, bus waiting times, and bus engine capacity. The engine capacity data is used to calculate fuel consumption based on the Taylor equation. The bus activities studied were intercity, interprovincial and provincial buses (AKAP-AKDP) and city buses. Primary data collection is in the form of waiting time for AKAP-AKDP buses and city buses while waiting for passengers in May 2019. Observation of the bus waiting time is carried out at 06.00-10.00 and 16.00-20.00 GMT+7. The results of GHG emission calculations show that the AKAP-AKDP bus $\mathrm{CO}_{2}$ eq emissions during idling condition are 1,147.92 tons/year and city buses are 831.63 tons/year.
\end{abstract}

Keywords: bus activity, greenhouse gas, idling condition, Purabaya Station, Taylor equation

\begin{abstract}
Abstrak
Terminal Purabaya merupakan terminal terbesar di Jawa Timur. Aktivitas bus di dalam terminal berpotensi pada peningkatan emisi gas rumah kaca (GRK). Penelitian ini bertujuan menganalisis emisi gas rumah kaca dari aktivitas bus pada saat diam namun dengan kondisi mesin menyala di Terminal Purabaya (kondisi idle). Emisi tersebut berasal dari konsumsi bahan bakar pada saat mesin bus menyala. Parameter udara gas rumah kaca pada penelitian ini adalah gas $\mathrm{CO}_{2}, \mathrm{CH}_{4}$, dan $\mathrm{N}_{2} \mathrm{O}$ yang dinyatakan dalam $\mathrm{CO}_{2}$ ekuivalen $\left(\mathrm{CO}_{2 e q}\right)$. Perhitungan emisi GRK menggunakan persamaan Taylor. Perhitungan tersebut membutuhkan data jumlah kendaraan bus, waktu tunggu bus, dan kapasitas mesin bus. Data kapasitas mesin itu digunakan untuk menghitung konsumsi bahan bakar berdasarkan persamaan Taylor. Aktivitas bus yang diteliti adalah bus Antar Kota Antar Provinsi dan Dalam Provinsi (AKAP-AKDP) serta bus kota. Pengambilan data primer berupa waktu tunggu bus AKAP-AKDP dan bus kota ketika menunggu penumpang pada Bulan Mei 2019. Pengamatan waktu tunggu bus tersebut dilakukan pada jam 06.00-10.00 dan 16.00-20.00 WIB. Hasil perhitungan emisi GRK menunjukkan emisi $\mathrm{CO}_{2}$ eq bus AKAP-AKDP pada saat kondisi idle sebesar 1.147,92 ton/tahun dan bus kota sebesar 831,63 ton/tahun.
\end{abstract}

Kata Kunci: aktivitas bus, gas rumah kaca, kondisi idle, Persamaan Taylor, Terminal Purabaya 


\section{Pendahuluan}

Perkembangan kegiatan ekonomi beriringan dengan meningkatnya kebutuhan akan transportasi baik dalam kota maupun antar kota. Berdasarkan Badan Pusat Statistik Surabaya, pada tahun 2015 jumlah kendaraan meningkat $1,05 \%$ dibandingkan dengan jumlah kendaraan pada tahun 2014. Salah satu jenis kendaraan yang mengalami peningkatan jumlah adalah angkutan bus dan sejenisnya. Salah satu pendukung aspek pariwisata yaitu tersedianya fasilitas transportasi umum yang memadai, salah satunya adalah Terminal Purabaya.

Terminal Purabaya merupakan terminal tipe A terbesar di Jawa Timur. Terminal Purabaya melayani angkutan Antar Kota Antar Provinsi (AKAP), angkutan Antar Kota Dalam Provinsi (AKDP), dan angkutan kota serta terhubung dengan angkutan non-trayek seperti lynn, bison, dan taksi (Amiruddin, 2017). Data dari Dinas Perhubungan Surabaya tahun 2018 menunjukkan jumlah keberangkatan bus tahun 2017 sebanyak 337.000 kali dan kedatangan 205.891 kali. Aktivitas bus yang tinggi di dalam terminal tersebut dapat menyebabkan peningkatan emisi gas rumah kaca (GRK). Menurut Aswad (2018), aktivitas kendaraan umum di terminal mempunyai potensi yang cukup besar dalam menghasilkan emisi GRK. Wangi (2016) menambahkan dalam penelitiannya bahwa kendaraan bus memberikan kontribusi yang cukup besar terhadap emisi GRK.

Gas di atmosfer dapat berkontribusi pada efek rumah kaca baik secara langsung maupun tidak langsung. Efek langsung terjadi ketika gas itu sendiri menyerap radiasi. Sedangkan radiasi tidak langsung terjadi ketika transformasi kimiawi zat menghasilkan gas rumah kaca lainnya, ketika gas mempengaruhi masa hidup atmosfer dari gas lain, dan/atau ketika gas mempengaruhi proses atmosfer yang mengubah keseimbangan radiasi bumi (U.S. EPA, 2014). Menurut Mikhalov dkk. (2020), bahan bakar dari transportasi berkontribusi terhadap emisi GRK sebesar 13,2\%. Gas $\mathrm{CO}_{2}$ mempunyai kontribusi sebesar $72 \%$ terhadap total emisi GRK, gas metan sebesar $20 \%$, sedangkan gas $\mathrm{N}_{2} \mathrm{O}$ sebesar 5\%. Ollila (2019) mengatakan bahwa temperatur udara di atmosfer semakin bertambah seiring dengan meningkatnya konsentrasi $\mathrm{CO}_{2}$ di atmosfer. Oleh karena itu, gas rumah kaca secara tidak langsung menyebabkan pemanasan global. Handriyono (2019) menambahkan bahwa pada pemanasan global terjadi akibat peningkatan akumulasi gas rumah kaca.

Penelitian ini menghitung emisi GRK berupa gas $\mathrm{CO}_{2}, \mathrm{CH}_{4}$, dan $\mathrm{N}_{2} \mathrm{O}$ dari aktivitas kendaraan bus pada saat kondisi idling di Terminal Purabaya. Kondisi idling adalah kondisi dimana kendaaran diam namun mesin menyala. Pemilihan lokasi Terminal Purabaya didasari atas pertimbangan Terminal Purabaya merupakan terminal terbesar di Jawa Timur dengan angka kedatangan dan keberangkatan bus yang tinggi setiap tahunnya sehingga aktivitas kendaraan bus dianggap tinggi dan berpotensi menghasilkan emisi GRK. Harapan penelitian ini adalah pengelola Terminal Purabaya mempunyai pertimbangan dalam pengaturan waktu idling bus. Selain itu juga tercipta mitigasi dalam pengendalian emisi GRK di kawasan Terminal.

\section{Metode}

Perhitungan emisi GRK membutuhkan data primer berupa waktu tunggu bus serta data sekunder berupa jumlah kendaraan bus dan kapasitas mesin bus. Data jumlah kendaraan bus berasal dari Dinas Perhubungan Kota Surabaya. Waktu tunggu adalah waktu dimana bus menunggu penumpang ketika bus mulai memasuki peron. Waktu pengamatan tersebut pada bulan Mei 2019 pada jam 06.00-10.00 dan 16.00-20.00. Pemilihan waktu tersebut berdasarkan pertimbangan jam sibuk di Terminal Purabaya. Pengamatan bus berupa bus Antar Kota Antar Provinsi dan Antar Kota Dalam Provinsi (AKAP-AKDP) serta bus kota. Perhitungan emisi GRK menggunakan persamaan Taylor (2003) berikut:

$$
\text { Emisi Idle }=Y \times \text { Idle Time } \times \mathrm{Nb} \times \mathrm{FE}
$$

Keterangan: 


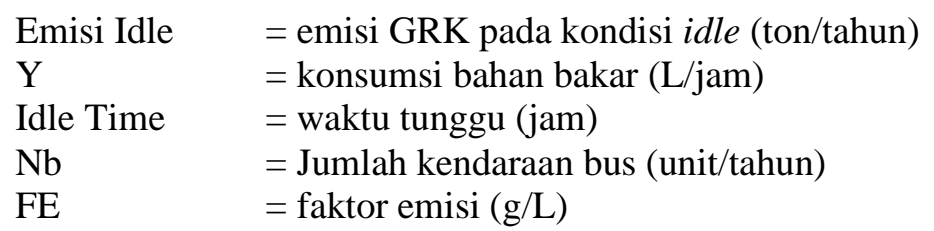

Taylor (2003) menganalisis hubungan antara kapasitas mesin bus terhadap aliran bahan bakar pada saat kondisi idling sehingga menghasilkan persamaan berikut:

$$
Y=0,3644 \quad X+0,5188
$$

Keterangan:

$\mathrm{Y} \quad=$ konsumsi bahan bakar $(\mathrm{L} / \mathrm{jam})$

$\mathrm{X} \quad=$ kapasitas mesin $(\mathrm{L})$

Faktor Emisi menggunakan data dari IPCC (International Panel of Climate Change) Tahun 2006 untuk kendaraan bus dengan bahan bakar solar (Tabel 1).

Tabel 1: Faktor Emisi dari Kendaraan Bus Berbahan Bakar Solar

\begin{tabular}{cccc}
\hline \multirow{2}{*}{ Jenis Kendaraan } & \multicolumn{3}{c}{ Faktor Emisi (gram/liter) } \\
\cline { 2 - 4 } & $\mathbf{C O}_{\mathbf{2}}$ & $\mathbf{C H}_{\mathbf{4}}$ & $\mathbf{N}_{\mathbf{2}} \mathbf{O}$ \\
\hline Bus & 2924,90 & 0,24 & 0,16 \\
\hline Sumber: $I P C C, 2006$ & & &
\end{tabular}

Setelah mendapatkan emisi tiap parameter GRK, kemudian menyetarakan emisi GRK itu menjadi $\mathrm{CO}_{2}$ ekuivalen $\left(\mathrm{CO}_{2 \mathrm{eq}}\right)$ berdasarkan nilai Global Warning Potential (GWP). Nilai tersebut menunjukkan ukuran untuk membandingkan potensi GRK dalam memanaskan bumi pada periode tertentu dan disetarakan dengan nilai potensi gas $\mathrm{CO}_{2}$. Nilai GWP untuk gas $\mathrm{CH}_{4}$ adalah 25 sedangkan nilai GWP gas $\mathrm{N}_{2} \mathrm{O}$ sebesar 298 (IPCC, 2007).

Data jumlah kendaraan bus yang diperoleh dari Dinas Perhubungan diambil sampel dengan menggunakan persamaan Slovin pada persamaan (3).

$$
n=\frac{N}{N\left(d^{2}\right)+1}
$$

Keterangan:

$\mathrm{n} \quad=$ jumlah sampel

$\mathrm{N} \quad=$ jumlah populasi

$\mathrm{d} \quad=$ tingkat kesalahan

Hasil perhitungan sampel kendaraan bus tersebut digunakan untuk mengamati waktu tunggu kendaraan bus di Terminal Purabaya. Batasan studi ini adalah emisi GRK yang diamati hanya dari kendaraan bus yang beroperasi di Terminal Purabaya. Untuk data konsumsi bahan bakar kendaraan yang diamati hanya bahan bakar solar. Jenis mesin, kondisi kendaraan, serta tahun pembuatan diabaikan pada penelitian ini.

\section{Hasil dan Pembahasan}

Terminal Purabaya merupakan pengembangan dari Terminal Joyoboyo yang kapasitasnya sudah tidak memadai. Lokasi terminal berada dipusat kota yang tidak memungkinkan dilakukan pengembangan. Lokasi pembangunan terminal Purabaya berada di desa Bungurasih, Kecamatan Waru, Kabupaten Sidoarjo dengan luas $\pm 12 \mathrm{Ha}$. Dipilihnya lokasi tersebut karena mempunyai akses yang sangat baik dan strategis sebagai pintu masuk ke kota Surabaya serta berada pada jalur keluar kota Surabaya di arah timur selatan dan barat. Meskipun lokasi terminal Purabaya berada di Kabupaten Sidoarjo namun pengelolaan terminal dilakukan oleh Pemerintah Kota Surabaya. Hal tersebut berdasarkan perjanjian 
kerjasama (MOU) antara Pemerintah Kabupaten Sidoarjo dengan Pemerintah Kota Surabaya (Amirudin, 2017).

Terminal Purabaya merupakan terminal Tipe A dengan luas lahan sebesar 12 Ha yang beroperasi selama 24 jam. Kapasitas terminal Purabaya mencakup 16 lajur pemberangkatan bus AKDP, 10 lajur pemberangkatan bus AKAP/Malam, 10 Lajur pemberangkatan bus kota, 1 lajur pemberangkatan bus bandara, 3 lajur kedatangan bus antar kota, 2 lajur pemberangkatan MPU, dan 2 lajur taksi dan mobil pribadi. Terdapat 3 jenis bus yang beroperasi di Terminal Purabaya antara lain bus AKAP, bus AKDP, dan bus kota.

Jalur AKAP dibagi menjadi dua, yaitu jalur utara dan selatan sedangkan jalur AKDP dibagi menjadi 4, yaitu jalur Barat I, Barat II, Timur, Selatan, dan Madura. Pada gerbang keberangkatan terminal tersedia 24 jalur yang terisi tujuan bus dan terdapat 2 jalur kosong. Jalur kosong berada pada jalur 1 dan 16, sedangkan bus jenis patas, ekonomi, dan eksekutif berada pada 24 jalur yang lain. Keberangkatan bus kota terdapat 10 jalur yang terdiri dari bus kota ekonomi, patas, dan patas AC. Tabel 2 dan Tabel 3 merupakan jalur keberangkatan Bus Kota dan Bus AKAP-AKDP di Terminal Purabaya.

Tabel 2: Jalur Keberangkatan Bus Kota di Terminal Purabaya

\begin{tabular}{cll}
\hline Jalur & \multicolumn{1}{c}{ Tujuan } & \multicolumn{1}{c}{ Jenis } \\
\hline 1 & (A2) Purabaya -Ngagel-Semut PP & Ekonomi \\
2 & (D) Purabaya-Bratang PP & Ekonomi \\
3 & (E1) Purabaya-Joyoboyo PP & Ekonomi \\
4 & (F) Purabaya-Diponegoro PP & Ekonomi \\
5 & (P1) Purabaya-Darmo-Perak PP & Patas \\
6 & (P4) Purabaya-Tol Waru-Perak PP & Patas \\
7 & (P5) Purabaya-Tol Waru- Demak JMP PP & Patas \\
8 & (P6) Purabaya-Darmo-Perak PP & Patas \\
9 & (PAC1) Purabaya-Darmo-Perak PP & Patas AC \\
10 & (PAC8) Purabaya-Tol Waru-TOW & Patas AC \\
\hline
\end{tabular}

Sumber: Dinas Perhubungan (2019)

Tabel 3: Jalur Keberangkatan Bus AKAP-AKDP di Terminal Purabaya

\begin{tabular}{cll}
\hline Jalur & \multicolumn{1}{c}{ Tujuan } & \multicolumn{1}{c}{ Jenis } \\
\hline 1 & - & - \\
2 & Situbondo-Bondowoso-Banyuwangi & Patas \\
3 & Madura & Patas \\
4 & Pare-Wates-Blitar & Patas \\
5 & Probolinggo-Jember & Patas \\
6 & Kediri-Tulungagung-Trenggalek & Patas \\
7 & Malang-Blitar & Patas \\
8 & Nganjuk-Madiun-Ponorogo & Patas \\
9 & Malang-Blitar & Ekonomi \\
10 & Madura & Ekonomi \\
11 & Madiun-Ponorogo-Pacitan & Ekonomi \\
12 & Bondowoso-Jember-Banyuwangi & Ekonomi \\
13 & Kediri-Tulungagung-Trenggalek & Ekonomi \\
14 & Ambulu & Ekonomi \\
15 & Bojonegoro-Tuban-Cepu & Ekonomi \\
16 & - & - \\
17 & Purwokerto-Tsikmalaya-Bandung & Ekonomi \\
18 & Solo-Jogja & Ekonomi \\
19 & Tuban-Semarang-Cirebon & Ekonomi \\
20 & Solo-Jogja-Magelang-Semarang & Patas
\end{tabular}




\begin{tabular}{cll}
\hline Jalur & \multicolumn{1}{c}{ Tujuan } & \multicolumn{1}{c}{ Jenis } \\
\hline 21 & Tuban-Semarang & Patas \\
22 & Purwokerto-Cilacap & Eksekutif \\
23 & Denpasar-Mataram & Eksekutif \\
24 & Bogor-Bandung & Eksekutif \\
25 & Jakarta-Lampung & Eksekutif \\
26 & Tegal-Cirebon & Eksekutif \\
\hline
\end{tabular}

Sumber: Dinas Perhubungan (2019)

Data jumlah kendaraan kendaraan bus untuk aktivitas kendaraan diam atau idle menggunakan data keberangkatan bus AKAP-AKDP dan bus kota selama Tahun 2018. Data tersebut berasal dari Dinas Perhubungan Kota Surabaya yang diperoleh pada waktu Tahun 2019. Tabel 4 adalah data jumlah kendaraan bus di Terminal Purabaya Tahun 2018 dan jumlah sampel penelitian berdasarkan persamaan Slovin.

Tabel 4: Jumlah Sampel Kendaraan Bus

\begin{tabular}{ccc}
\hline Deskripsi & \multicolumn{2}{c}{ Jenis Kendaraan } \\
\cline { 2 - 3 } & Bus AKAP-AKDP & Bus Kota \\
\hline Jumlah bus Tahun 2018 & 387.516 & 176.901 \\
Rata-rata per hari & 1.076 & 491 \\
Jumlah sampel & 291 & 221 \\
\hline
\end{tabular}

Sumber: Hasil Perhitungan

Setelah mendapatkan jumlah sampel bus yang akan diteliti, kemudian dilakukan pengamatan waktu tunggu bus, kapasitas mesin bus, dan perhitungan konsumsi bahan bakar menggunakan persamaan (2). Waktu tunggu merupakan lama waktu yang dibutuhkan kendaraan bus AKAP-AKDP dan bus kota saat menunggu di terminal keberangkatan hingga kendaraan bus berangkat dalam keadaan mesin menyala. Metode pengamatan dilakukan secara langsung pada setiap bus yang menunggu penumpang sampai bus tersebut berjalan. Tabel 5 merupakan hasil rekapitulasi waktu tunggu rata-rata bus AKAPAKDP di Terminal Purabaya.

\begin{tabular}{lc}
\multicolumn{2}{c}{ Tabel 5: Waktu Tunggu Rata-rata Bus di Terminal Purabaya } \\
\hline Jenis Kendaraan & $\begin{array}{c}\text { Waktu tunggu rata-rata } \\
\text { (Jam) }\end{array}$ \\
\hline Bus AKAP-AKDP & 0,29 \\
Bus Kota & 0,46 \\
\hline \multicolumn{2}{c}{ Sumber: Hasil Perhitungan }
\end{tabular}

Salah satu faktor yang mempengaruhi konsumsi bahan bakar adalah kapasitas mesin. Data kapasitas mesin dikonversi dari cc menjadi liter untuk perhitungan konsumsi bahan bakar yang digunakan saat kendaraan diam atau idle. Hasil dari pengamatan di Terminal Purabaya melalui wawancara ke beberapa sopir bus, bus yang beroperasi memiliki kapasitas mesin dengan rentang 6000-8000 cc. Perbedaan jenis kendaraan serta tahun produksi mengakibatkan adanya perbedaan kapasitas mesin, namun untuk jenis bahan bakar yang digunakan, bus yang beroperasi menggunakan bahan bakar solar. Berdasarkan data dari Dinas Perhubungan Kota Surabaya kapasitas mesin bus adalah $8000 \mathrm{cc}$ atau 8 liter. Oleh karena itu perhitungan konsumsi bahan bakar kendaraan menggunakan data kapasitas mesin bus yang berasal dari Dinas Perhubungan Kota Surabaya dengan pertimbangan lebih valid karena dari lembaga yang berwenang.

Setelah mengetahui kapasitas mesin bus, kemudian dihitung konsumsi bahan bakar saat bus dalam kondisi diam (idling). Salah satu contoh perhitungan konsumsi bahan bakar kendaraan saat keadaan diam atau idle dengan data kapasitas mesin diatas adalah sebagai berikut:

Jenis kendaraan $\quad$ : Bus Besar 
Fungsi konstanta y $\quad: \mathrm{y}=0,3644 \mathrm{x}+0,5188$

Kapasitas mesin : 8 liter

Konsumsi bahan bakar :

$\mathrm{y}=0,3644 \mathrm{x}+0,5188$

$\mathrm{y}=0,3644(8)+0,5188$

$\mathrm{y}=3,43 \mathrm{~L} / \mathrm{jam}$

Tabel 6 adalah hasil perhitungan konsumsi bahan bakar saat bus pada kondisi idling di Terminal Purabaya.

Tabel 6: Konsumsi Bahan Bakar Bus saat kondisi diam (idling) di Terminal Purabaya

\begin{tabular}{lc}
\hline \multicolumn{1}{c}{ Jenis Kendaraan } & Konsumsi bahan bakar (L/jam) \\
\hline Bus AKAP-AKDP & 3,43 \\
Bus Kota & 3,43 \\
\hline \multicolumn{2}{c}{ Sumber: Hasil Perhitungan }
\end{tabular}

Perhitungan emisi GRK menggunakan persamaan Taylor. Hasil perhitungan emisi gas $\mathrm{CH}_{4}$ dan $\mathrm{N}_{2} \mathrm{O}$ disetarakan menggunakan nilai Global Warming Potential (GWP) sehingga menghasilkan $\mathrm{CO}_{2}$ ekuivalen $\left(\mathrm{CO}_{2 \text {-eq }}\right)$. Nilai GWP untuk gas $\mathrm{CH}_{4}$ adalah 25 sedangkan nilai GWP gas $\mathrm{N}_{2} \mathrm{O}$ sebesar 298 (IPCC, 2007). Contoh perhitungan emisi gas rumah kaca kendaraan diam adalah sebagai berikut:

Jenis Kendaraan

: Bus Besar (Niaga Besar)

Data Aktivitas

: Kendaraan Bus AKAP-AKDP Kedatangan

Jumlah Kendaraan setahun $\quad: 387.516$

Konsumsi Bahan Bakar $\quad$ : 3,43 liter/jam

Konsumsi Bahan Bakar bus dalam setahun :

$=$ konsumsi bahan bakar $\times$ waktu tunggu $\times$ kendaraan setahun

$=3,43 \mathrm{~L} / \mathrm{jam} \times 0,29 \mathrm{jam} \times 387.516 /$ tahun

$=385.462,2 \mathrm{~L} /$ tahun

Emisi $\mathrm{CO}_{2}$ dalam setahun:

$=$ konsumsi bahan bakar $\mathrm{x}$ faktor emisi

$=\frac{385.362,2 \mathrm{~L} / \text { tahun }}{1.000 .000 \mathrm{gr} / \mathrm{ton}}$

$=1.127,43$ ton/tahun

Tabel 7 merupakan hasil perhitungan emisi GRK dari kendaraan bus diam (idling) di Terminal Purabaya.

Tabel 7: Emisi GRK dari Kendaraan Bus Diam (Idling) di Terminal Purabaya

\begin{tabular}{|c|c|c|c|c|}
\hline \multirow[t]{2}{*}{ Jenis Kendaraan } & \multicolumn{3}{|c|}{ Emisi GRK (ton/tahun) } & \multirow{2}{*}{$\begin{array}{c}\text { Emisi GRK } \\
\text { COO-eq } \\
\text { (ton/tahun) }\end{array}$} \\
\hline & $\mathrm{CO}_{2}$ & $\mathrm{CH}_{4}$ & $\mathrm{~N}_{2} \mathrm{O}$ & \\
\hline Bus AKAP-AKDP & $1.127,43$ & 0,09 & 0,06 & $1.147,92$ \\
\hline Bus Kota & 816,38 & 0,07 & 0,04 & 831,63 \\
\hline
\end{tabular}

Sumber: Hasil Perhitungan 
Hasil perhitungan menunjukkan bahwa emisi gas rumah kaca $\mathrm{CO}_{2}$ ekuivalen yang dihasilkan selama setahun saat kendaraan diam oleh bus AKAP-AKDP adalah 1.147,92 ton/tahun sedangkan bus kota sebesar 831,63 ton/tahun, sehingga total emisi GRK adalah 1.979,55 ton/tahun. Berdasarkan data Badan Pusat Statistik (2019), emisi GRK dari sektor energi dan transportasi pada Tahun 2017 sebesar 558,89 MTon/tahun. Hal tersebut menunjukkan emisi GRK yang berasal dari aktivitas kendaraan bus pada saat kondisi idling mempunyai kontribusi sebesar 0,00035\% terhadap emisi GRK Nasional dari sektor energi dan transportasi. Sektor energi dan transportasi menjadi penyumbang terbesar terhadap emisi GRK total di Indonesia yakni sebesar $65,7 \%$.

Emisi gas rumah kaca $\mathrm{CO}_{2}$ ekuivalen untuk aktivitas kendaraan diam bus AKAP-AKDP memiliki nilai lebih besar dibandingkan dengan aktivitas kendaraan diam bus kota. Konsumsi bahan bakar memiliki nilai yang sama dikarenakan kapasitas mesin yang sama sehingga konsumsi bahan bakar yang mengalir per jamnya sama. Selain itu, jumlah kendaraan selama setahun antara bus AKAP-AKDP dan bus kota memiliki perbedaan yang cukup jauh sehingga emisi $\mathrm{CO}_{2}$ ekuivalen bus AKAP-AKDP lebih besar daripada bus kota. Gambar 1 merupakan grafik hasil perhitungan emisi gas rumah kaca $\mathrm{CO}_{2}$ ekuivalen berdasarkan aktivitas kendaraan diam di Terminal Purabaya.

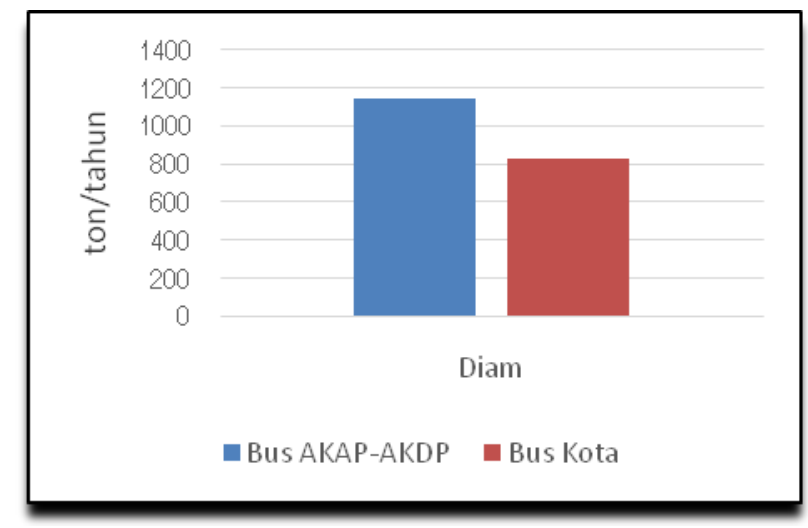

Gambar 1: Perbandingan Emisi $\mathrm{CO}_{2 \text {-eq }}$ Bus AKAP-AKDP dan Bus Kota

Selain akibat jumlah kendaraan yang lebih banyak dibandingkan dengan bus kota, bus AKAP-AKDP dalam kondisi idling memiliki waktu tunggu yang lebih lama. Menurut Sarwar (2017), kondisi mesin idling selama 10 menit setara dengan kendaran bergerak yang menempuh jarak sejauh 8 kilometer. Purwanto (2015) menambahkan bahwa pembakaran yang terjadi saat kondisi idling tidak efisien dan tidak sempurna sehingga terjadi pengumpulan senyawa-senyawa yang dikeluarkan oleh kendaraan bermotor pada satu tempat.

Penelitan ini perlu melanjutkan pengukuran emisi secara langsung terhadap kendaraan bus di Terminal Purabaya. Hal tersebut untuk mempertegas upaya pengendalian emisi GRK bagi pengelolaan di Terminal Purabaya. Hasil pengukuran tersebut diharapkan dapat memberikan rekomendasi aksi mitigasi, contohnya yaitu Eco Smart Driving (ESD) berupa batasan waktu yang diperbolehkan untuk bus menyalakan mesin saat menunggu penumpang.

\section{Kesimpulan}

Hasil penelitian menunjukkan kesimpulan bahwa waktu tunggu bus kota di Terminal Purabaya lebih lama daripada bus AKAP-AKDP. Kapasitas mesin bus sebesar $8000 \mathrm{cc}$ menghasilkan konsumsi bahan bakar sebesar 3,43 L/jam. Emisi $\mathrm{CO}_{2 \text {-eq }}$ bus AKAP-AKDP sebesar 1.147,92 ton/tahun lebih besar daripada bus kota sebesar 831,63 ton/tahun. Hasil perhitungan menunjukkan Total emisi $\mathrm{CO}_{2 \text {-eq }}$ dari kendaraan bus pada kondisi diam (idle) di Terminal Purabaya adalah 1.979,55 ton/tahun. Rekomendasi penelitian ini adalah membuat aksi mitigasi berupa batasan waktu yang diperbolehkan untuk bus menyalakan mesin saat menunggu penumpang. 


\section{Daftar Pustaka}

Amiruddin, M. T. (2017). Konflik Kewenangan Pemerintah Kota Surabaya dan Pemerintah Kabupaten Sidoarjo dalam Pengelolaan Terminal Purabaya. Skripsi UINSA.

Aswad, G. dan Cahyonugroho, O. H. (2018). Potensi Gas Rumah Kaca (GRK) dari Aktivitas Angkutan Umum di Terminal Tamanan Kota Kediri. Jurnal Envirotek, 10, (1), 46-52.

Badan Pusat Statistik Kota Surabaya. (2015). Banyaknya Kendaraan Bermotor Menurut Jenisnya 2009-2015. Surabaya.

Handriyono, R. E., Sutanto, J. E., dan Putra, G. R. G. (2019). Studi Beban Emisi Gas Metan (CH4) dari Kegiatan Peternakan di Desa Galengdowo Jombang. Jurnal Pengabdian Masyarakat Ipteks, 5, (2), 119-123.

IPCC. (2006). Guidelines for National Greenhouse Gas Inventories. Volume 2: Energy.

IPCC. (2007). Climate Change 2007: Snynthesis Report. Contribution of Working Groups I, II, and III to the Fourth Assesment Report of the Intergovernmental Panel on Climate Change. Geneva. Switzerland.

Mikhalov, A., Moiseev, N., Aleshin, K., dan Bukhardt, T. (2020). Global Climate Change and Greenhouse Effect. Journal of Entrepreneurship and Sustainability Issues, 7, (4), 2897-2913.

Purwanto, C. P., Arthana, I W., dan Suarna, I W. (2015). Inventarisasi Emisi Sumber Bergerak di Jalan (On Road) Kota Denpasar. Jurnal Ecotrophic, 9, (1), 1-9.

Sarwar, M. S., Ullah, S., Farooq, dan U., Zohair, M. (2017). Engine Idling: A Major Cause of CO Emissions and Increased Fuel Costs. International Journal of Operations and Logistics Management, 6, (2), 44-54.

Taylor, G. W. R. (2003). Review of The Incidence Energy Use and Costs of Passenger Vehicle Idling. GW Taylor Consulting. Canada.

Wangi, L. S., Huboyo, H. S., dan Wardhana I. W. (2016). Kajian Emisi Gas Rumah Kaca $\left(\mathrm{CO}_{2}, \mathrm{CH}_{4}, \mathrm{~N}_{2} \mathrm{O}\right)$ Akibat Aktivitas Kendaraan (Studi Kasus Terminal Mangkang dan Terminal Penggaron). Jurnal Teknik Lingkungan, 5, (5), 1-10.

U.S. EPA. (2014). Inventory of U.S. Greenhouse Gas Emissions and Sinks: 1990-2012. Washington. U.S.A. 